\title{
Clasificación y producción de beneficiarios en una política de prevención social del delito
}

\author{
Classification and Production of Beneficiaries Within a Policy of Social \\ Crime Prevention \\ Classificação e produção de beneficiários em uma política de prevenção \\ social do delito
}

\author{
INÉS MANCINI
}

FECHA DE RECEPCIÓN: 31 DE JULIO DE 2015. FECHA DE ACEPTACIÓN: 22 DE OCTUBRE DE 2015

Doi: dx.doi.org/10.12804/esj18.01.2016.04

Para citar este artículo: Mancini, I. (2016). Clasificación y producción de beneficiarios en una política de prevención social del delito. Estudios Socio-Jurídicos, 18(1), 105-135. Doi: dx.doi.org/10.12804/esj18.01.2016.04

\section{RESUMEN}

Este trabajo analiza los modos en los que jóvenes residentes en villas de emergencia de la ciudad de Buenos Aires pueden ser clasificados como beneficiarios por una política de prevención social del delito. A partir de esta construcción, se intenta reflexionar acerca de las consecuencias concretas que las modalidades de clasificación y admisión de los jóvenes en el programa tienen en el desarrollo del programa mismo y en las vidas de los jóvenes.

Palabras clave: políticas sociales, prevención social del delito, jóvenes, estigma.

\begin{abstract}
This paper analyzes the ways in which young people living Buenos Aires slums can be classified as beneficiaries in a crime prevention social policy. We reflect on classification and its consequences in the program and in young people's lives.
\end{abstract}

Keywords: Social policies, social prevention of crime, youth, stigma.

\section{RESUMO}

Este trabalho analisa as formas em que os jovens residentes em favelas de emergência da Cidade de Buenos Aires podem ser classificados como beneficiários por uma política de prevenção social do delito. A partir desta construção, tenta-se refletir acerca das consequências concretas que as modalidades de classificação e admissão dos jovens no programa têm no desenvolvimento do programa e nas vidas dos jovens.

Palavras- chave: Políticas sociais, prevenção social do delito, jovens, estigma.

* Inés Mancini es Licenciada en Sociología (Facultad de Ciencias Sociales, UBA), Magister en Antropología Social y Política (FLACSO Argentina) y Doctora en Antropología Social (IDAES; UNSAM). Ha recibido distintas becas de investigación y ha sido docente de la Facultad de Ciencias Sociales, UBA y de la Universidad de San Martín, entre otras casas de estudio. En la actualidad, es becaria postdoctoral de CONICET, con sede en IDAES UNSAM. Se especializa en el análisis de políticas de prevención social del delito, en particular en la reflexión sobre los niveles de apropiación de estas políticas por parte de los destinatarios. Correo electrónico: inesmmancini@gmail.com 


\section{Introducción}

Las políticas sociales dirigidas a jóvenes y las políticas destinadas a la prevención social del delito son materia de interrogación en la literatura académica. Uno de los aspectos más discutidos se relaciona con los grados de estigmatización que se atribuyen a la implementación de políticas de prevención social del delito (Sozzo, 2000; Dallorso, 2008; Ayos y Dallorso, 2011).

Suelen discutirse los grados de estigmatización asociados con la producción de clasificaciones centradas en las nociones de riesgo; sin embargo, entendemos que es preciso considerar un análisis que tome en cuenta las implementaciones de los programas, para dar cuenta de una interacción dinámica y compleja que no suele ser alcanzada cuando se revisan los aspectos programáticos de una política pública.

Entendemos que es preciso ahondar en esas reflexiones desde un estudio de caso que considera la práctica del programa. Así, nos ocupamos del análisis de la aplicación del Programa Comunidades Vulnerables en una villa de emergencia de la ciudad de Buenos Aires (Argentina).

El programa se enmarcaba en el Plan Nacional de Prevención del Delito y fue diseñado a fines de 2001. Según su propia definición, se trata de un modelo específico de abordaje territorial centrado en la integración social y la prevención del delito y de la violencia (Ciafardini, 2005). Sus objetivos consisten en garantizar el acceso de jóvenes de comunidades vulnerables a sus derechos fundamentales; incidir sobre los factores vinculados a los procesos de vulneración social y reducir los índices de criminalidad, reincidencia y violencia (Ciafardini, 2005).

La ejecución del programa estuvo a cargo de la Dirección de Política Criminal del Ministerio de Justicia y Derechos Humanos de la Nación (Argentina). En algunos territorios, esta entidad apuntaba a que cada Gobierno local ejecutara el programa, asistido y supervisado por funcionarios del Gobierno nacional, mientras otros eran trabajados mediante la inserción de operadores del Estado nacional. En 2008, el programa dejó de desarrollarse en el ámbito nacional y, desde entonces, solo continuaron trabajando los Gobiernos locales que lo consideraron pertinente.

En la práctica, el funcionamiento del programa implicaba la asistencia de operadores a una comunidad vulnerable o territorio en donde se ejecutaban diversas actividades con los beneficiarios del programa: talleres sobre 
temáticas propuestas por el programa (por ejemplo, identidad), también se abordaban problemáticas que los operadores consideraban pertinentes para un grupo de beneficiarios en particular (por ejemplo, talleres sobre búsqueda de empleo, organización del tiempo o de género) y se hacían salidas o actividades puntuales por demandas específicas de los beneficiarios.

Un aspecto central a tener en cuenta es que el programa articula sus acciones con el Ministerio de Trabajo, lo que permite a los beneficiarios percibir un Plan de Empleo Comunitario (PEC), cuyo monto alcanzaba los $\$ 150^{1}$ mensuales y se cobraba en una entidad bancaria. Esta cuestión es fundamental, puesto que el dinero funciona como mediador de la relación entre operadores y beneficiarios. Uno de los efectos más notorios (tanto desde la perspectiva de los beneficiarios como de los operadores) de la desvinculación del programa consiste en dejar de percibir este ingreso mensual.

Los datos empíricos sobre los cuales se basa esta tesis se referirán a la observación de un grupo de operadores del Gobierno nacional asignados a una villa de emergencia ${ }^{2}$ situada en la ciudad de Buenos Aires. Si bien la aplicación del programa estuvo a cargo de funcionarios del Gobierno nacional, la implementación requirió de distintas formas de colaboración por parte de la sociedad civil. ${ }^{3}$

En esta villa, ${ }^{4}$ el programa era desarrollado por operadores ${ }^{5}$ del Gobierno nacional y por operadores del Gobierno de la ciudad de Buenos Aires.

1 En 2005, a comienzos de mi trabajo de campo, esta suma equivalía a cerca de 52 dólares y descendió a 47 dólares hacia 2007.

2 Entre 1930 y 1940 se produjeron las migraciones internas más significativas, lo que implica un encuentro entre "dos Argentinas" y el establecimiento de "villas de emergencia", cuyo punto más álgido de tensión se vivió entre 1945 y 1955, cuando estos migrantes fueron denominados "cabecita negra". A partir de entonces, hasta 1970, cobró importancia el mote de "villero" (Ratier, 1975; Guber, 1998).

Se construye la caracterización de un actor al que se le atribuye un alineamiento con el peronismo y pautas de vida diferentes a las de las clases medias urbanas, pues se entiende que preservan usos y costumbres de sus provincias de origen. Además, esta caracterización es acompañada por juicios morales: el villero es un actor caracterizado por una supuesta anomia, despreocupado por su propio progreso material o por el porvenir de sus hijos. Es una imagen construida desde los valores de las clases medias y de la burguesía porteña; sin embargo, algunos de estos rasgos pasan a constituir parte de la identidad social del villero (Guber, 1998).

3 Para un análisis detallado de las formas de participación de la sociedad civil en el marco de este programa, puede verse Mancini $(2012 ; 2015)$.

4 Para preservar la confidencialidad, todos los nombres propios que utilizamos son ficticios. Además, nos referiremos a esta villa de emergencia como "la villa", como la llaman algunos de sus habitantes.

5 Para un análisis más detallado de las trayectorias de los operadores, puede verse Mancini 
Los mismos operadores vinculados al Gobierno nacional que coordinaban el trabajo con un grupo de beneficiarios supervisaban el trabajo de los operadores del Gobierno local que trabajaban con otro grupo de jóvenes. Cuando el programa dejó de desarrollarse en el ámbito nacional, los beneficiarios comenzaron a trabajar con operadores del Gobierno de la ciudad.

Como se señaló, se trata de una política de prevención social del delito que buscaba trabajar con jóvenes en conflicto real o potencial con la ley penal. Para ello, recluta jóvenes que, tras un proceso de admisión, comienzan a trabajar asistiendo a dos reuniones semanales con los operadores.

En este trabajo nos proponemos reflexionar acerca de las clasificaciones operadas por distintos agentes intervinientes en la aplicación del programa Comunidades Vulnerables. La reflexión es importante, porque en los procesos de reclutamiento, admisión y clasificación de beneficiarios en políticas de prevención anidan discusiones sobre nuevos procesos de exclusión, estigmatización y criminalización. Como sostiene Llobet (2013), se trata de analizar procesos de categorización, clasificación y negociación desplegados en los programas, tanto en el espacio de la intervención como en las definiciones programáticas.

Nuestra propuesta consiste en tomar en consideración aquello que se señala acerca del beneficiario en el diseño del programa, pero también analizar lo que ocurre en la práctica cuando el programa es aplicado. En efecto, se trata de desentrañar los procesos microsociales de exclusión institucional en políticas de inclusión social (Llobet, 2013).

Los datos analizados en este artículo corresponden a la investigación adelantada para mi tesis doctoral. Dichos datos fueron recogidos a partir de una etnografía de la aplicación del Programa de Comunidades Vulnerables en una villa de emergencia de la ciudad de Buenos Aires. Además, se entrevistó a funcionarios y vecinos del barrio y se analizó la documentación del programa. La metodología de trabajo consistió en una etnografía desarrollada entre 2005 y 2008 . Observamos reuniones de operadores en su oficina de trabajo, las reuniones de trabajo entre operadores y jóvenes,

(2015). En términos generales, señalamos que en el diseño del programa no hay requerimiento de formación específica para ser operador. Además, es pertinente indicar que hay dos tipos de operador: los que conciben su trabajo en términos de militancia y fundan su relación con los jóvenes a partir del carisma y los que han hecho una carrera dentro del Estado y toman su vínculo con los jóvenes como un trabajo regulado por reglas. 
así como también hicimos trabajo de campo en las calles de la villa con los jóvenes. En todos los casos, registramos de modo sistemático lo observado en notas de campo. Algunos fragmentos de esas notas se reponen a lo largo del artículo, pues dan cuenta de las perspectivas involucradas en la aplicación del programa.

Nuestros hallazgos mostrarán que los procesos de clasificación y producción de beneficiarios son complejos cuando se toman en cuenta todas las perspectivas involucradas en la aplicación de una política de prevención social del delito. Ello implicará que aquellas cuestiones señaladas como estigmatizadoras por quienes estudian las políticas desde su diseño no son vistas de la misma forma cuando se analizan las interacciones observadas en su aplicación. En cambio, los posicionamientos morales de los agentes estatales (que serán estudiados a partir de las apreciaciones sobre las transferencias monetarias) pueden tener más incidencia en la producción de procesos microsociales de exclusión social.

\section{La definición del diseño}

En principio, el programa requiere para su funcionamiento de dos actores básicos: los operadores ${ }^{6}$ y los beneficiarios directos. En el diseño del programa se señalan algunos atributos esperados para los beneficiarios.

La definición programática postula que se debía apuntar a jóvenes entre 15 y 25 años que hubieran estado involucrados en prácticas violentas próximas al delito, que tuvieran una causa judicial abierta relacionada con actos de violencia y delitos callejeros, que hubieran estado en instituciones de encierro o que registraran, al menos, un ingreso a la comisaría en el último año (Ciafardini, 2005).

Además, se define a estos beneficiarios como directos en tanto son quienes participan activamente de las actividades del programa y perciben el beneficio económico. Se entiende que los familiares, vecinos y amigos de los beneficiarios son beneficiarios indirectos, dado que adquieren nuevas perspectivas que los beneficiarios directos estarán en condiciones de aportar.

6 Utilizaremos cursivas para destacar los términos nativos de los habitantes de la villa y los de la intervención estatal. 
Acordamos con lo señalado por Litichever, Magistris y Gentile (2013) respecto a que los programas definen quién es necesitado y cómo satisfacer esas necesidades; estas definiciones son entendidas como cristalizaciones de las operaciones de poder y prácticas sociales institucionalizadas.

La posibilidad de que una persona sea considerada beneficiaria depende de una clasificación. Como sostiene Herzfeld (1993), buena parte de la burocracia consiste en el manejo de taxonomías. Se verifica una construcción simbólica de la racionalidad burocrática, que implica procesos de conversión de estereotipos en descripciones de la realidad supuestamente objetivas que, más tarde, la interacción social reproduce y remodela. Así, el arte del juego de la burocracia consiste en naturalizar las propias acciones como lógicas apoyadas en bases autoevidentes.

En una línea argumentativa similar, Douglas (1996) señala que la institución necesita legitimarse mediante la naturaleza y la razón. Después, facilita a sus miembros un conjunto de analogías con el que explora el mundo. Luego, comienza a controlar la memoria de sus miembros, les suministra las categorías de pensamiento, fija la condiciones de autoconocimiento y establece identidades, a la vez que sacraliza ciertos principios de justicia.

Es importante destacar que, si bien existe en la descripción del programa una serie de indicaciones estadísticas que justificaría -al menos, en parte- el trabajo con la población que define para prevenir el delito, también es cierto que la idea de que el joven villero debe ser el objeto de esta política pública parece mucho más fundada en un estereotipo y la utilización superficial de estadísticas sirve para justificar esta naturalización. ${ }^{7}$ En todo caso, hay una llamativa coincidencia entre el estereotipo de joven pobre y delincuente y la población definida como potencial beneficiaria del programa.

7 Si bien los documentos consultados (Ciafardini, 2005; Ministerio de Justicia y Derechos Humanos, Dirección Nacional de Política Criminal, 2005) no presentan evidencia suficiente para justificar la selección del beneficiario, hay estudios que podrían justificar este tipo de selección. Míguez y D'Angelo (2006) plantean como hipótesis que el crecimiento de atentados contra la propiedad, protagonizados por menores en la década del noventa, se relacionó con un contexto en donde estos eran un recurso significativo como proveedores del hogar, a la vez que estaban en un mercado laboral en el que era difícil insertarse. Asimismo, Míguez (2008) aclara que lo que estudia no es la única cultura de la transgresión y reconoce que existió una judicialización de la pobreza, porque las dinámicas de la sociedad civil implicaron cada vez más a este mecanismo para intentar zanjar sus problemas de integración social con los menores. 
Guemureman (2015) analiza las políticas de control social en sentido amplio. Cuando analiza esta política, señala que los destinatarios terminan siendo los que están en riesgo, pero que aún no reciben el epíteto de intratables (como en las políticas destinadas a quienes ya fueron tomados por el sistema penal). Así, los conceptos de prevención y riesgo resultan clave y la noción de sujeto se sustituye por la de factor. Se trata de una política que, mediante la segmentación selectiva, tiene la pretensión de producir una transformación a futuro.

En efecto, el programa se define como un dispositivo para jóvenes en conflicto actual o potencial con la ley penal (Ministerio de Justicia y Derechos Humanos, Dirección Nacional de Política Criminal, 2005). La inclusión de la idea de que el beneficiario puede ser alguien en potencial conflicto con la ley puede interpretarse de un modo muy laxo; en el extremo, cualquier persona podría estar involucrada en esa definición.

Por otro lado, si solo fuera catalogado como alguien en conflicto con la ley penal para luego elevarlo a la categoría de beneficiario, no se podría beneficiar a quienes siguieran un comportamiento respetuoso del orden social vigente. Estas tensiones se hacen presentes en la práctica y delinean un conjunto de beneficiarios que, como veremos, incluye a personas que responden al perfil y a otras que no lo hacen. ${ }^{8}$ Se trata de una tensión que atiende, al mismo tiempo, a la búsqueda de diferenciarse de otras políticas sociales y a las demandas espontáneas de acceso a planes sociales.

La participación de los jóvenes está dividida en etapas. La primera es el reclutamiento, que consiste en la selección de los beneficiarios y la invitación a participar del programa. El dispositivo de admisión debe permitir a los operadores y jóvenes profundizar en el conocimiento mutuo antes de formalizar su incorporación definitiva. Este proceso tiene como objetivos: verificar la adecuación del perfil del postulante, explicar al interesado los propósitos y la modalidad de trabajo, evaluar la capacidad del interesado de adaptarse al encuadre, corroborar la firmeza de la decisión de participar y construir en forma conjunta el contrato institucional en el que se especifican prestaciones y responsabilidades entre las partes (Ciafardini, 2005).

8 De todos modos, si, como señala Kessler (2006), las barreras entre trabajo y delito son móviles, en el ámbito de la villa también resultarán fluidas las relaciones entre quienes cometen delitos y quienes no lo hacen. 
Por último, cabe señalar que la clasificación de una persona como beneficiaria no excluye la posibilidad de su movilidad. En efecto, un beneficiario, podría ser operador o un actor comunitario luego de vivir ciertas experiencias.

Los trabajos que solo toman la perspectiva programática encuentran en la definición del beneficiario una serie de problemas que redundan -en última instancia- en procesos de estigmatización y criminalización. No pretendemos sostener que la definición de este programa sea inocua, pues ninguna lo es; sin embargo, afirmamos que el análisis de este tipo de procesos con los que concluyen otros trabajos debe ser analizado tanto en el diseño como en la aplicación del programa. En efecto, es preciso poner en relación las definiciones programáticas con la aplicación de esas definiciones y analizar los procesos de construcción y apropiación de esas categorías programáticas.

\section{Las clasificaciones en la práctica}

El primer punto a tener en cuenta en la descripción del beneficiario al momento del reclutamiento es que existe una distancia importante entre las definiciones del diseño institucional del programa y las aplicaciones concretas de estas reglas que los operadores realizan en terreno. ${ }^{9}$

Por ejemplo, la edad (15 a 25) estipulada en el diseño institucional del programa se traduce, en la práctica, en una concentración en el límite inferior de edad, a partir de los 16 años, que es la edad estipulada por el PEC (dependiente de otro Ministerio) con el que trabajaba el programa. Esta preferencia por beneficiarios menores de 20 años se relacionaba con la idea de que el trabajo adelantado en otros barrios con jóvenes mayores no había resultado provechoso, puesto que se encontraban en un momento de mayor consolidación de su carrera delictiva. Al mismo tiempo, el hecho de que la mayoría de los integrantes del grupo fuera más joven incidía en que los nuevos integrantes también lo fueran, porque quienes pasaban algún tiempo en el programa solían recomendar a amigos o parientes.

9 Durante el tiempo que duró nuestro trabajo de campo, la composición del grupo de beneficiarios fue variando; esto nos brindó la posibilidad de observar los modos como los sujetos de intervención eran seleccionados. 
Nos hemos referido a las ambigüedades presentes en la definición y a la posibilidad que brindan de extender el término de beneficiario a todos los jóvenes de la villa. Si bien se especifican rasgos particulares que justifican la selección de algunos (y no todos) los jóvenes residentes en comunidades vulnerables, algunos de estos criterios como haber estado involucrado en prácticas violentas próximas al delito pueden ser interpretados con suficiente laxitud como para incluir a todos los jóvenes. De hecho, la tarea de definir qué constituye una práctica violenta próxima al delito es contingente y arbitraria..$^{10}$

Más allá de las ambigüedades o problemáticas presentes en la definición del perfil del beneficiario, en la práctica, los únicos requisitos que siempre se tenían en cuenta eran el de zona de residencia y edad. El trabajo se desarrolla con jóvenes residentes en comunidades vulnerables y en el programa se decide cuáles barrios constituyen el lugar de trabajo.

\subsection{Cómo llegar al beneficiario}

La traducción práctica de las categorías que componen el perfil de beneficiario del programa está sujeta a dos complicaciones: el tipo de persona, que presenta ciertas dificultades para ser vinculada y el reclutamiento, que implica dar dinero en un contexto de escasez en donde también hay muchas otras personas que demandan acceso al beneficio. Cuando leemos esas dos complicaciones en conjunto, nos encontramos ante una tensión: los beneficiarios más pertinentes no están al alcance, sino que hay que ir a buscarlos, mientras hay personas que están al alcance y solicitan ser incluidas de manera espontánea.

Se trata de un sujeto al que puede resultar difícil "reclutar", 11 por lo que se establecen ciertas estrategias para trabar una relación con el potencial beneficiario.

10 Por otra parte, pese a que ninguno de los actores involucrados en el diseño o la gestión de este programa estaría de acuerdo, este término guarda ciertas similitudes con la teoría de las ventanas rotas (Kelling y Coles, 1997) en la que se habla de conductas predelictuales. Aunque el tratamiento para la conducta predelictual es diferente desde cada una de estas políticas, la clasificación de un hecho cualquiera como próximo al delito se inscribe en una perspectiva que tendería a no diferenciar incivilidades de delito.

11 Hay literatura que se refiere a jóvenes de este perfil como jóvenes difíciles de alcanzar (Hendry, 2008). 
Como ya señalamos, los actores comunitarios desempeñan un rol destacado, pues ellos, junto con los beneficiarios, son quienes acercan a jóvenes que podrían clasificar como nuevos beneficiarios.

Ahora bien, además de conocer al beneficiario, es preciso que el joven cuente con un mínimo de iniciativa de ser parte del programa. En efecto, Guemureman (2015) señala que estas iniciativas implican que el individuo debe activarse, solicitar la adhesión a un programa y, luego, demostrar que se cumplen las responsabilidades.

No obstante, en la práctica, el programa implementa algunas estrategias para llegar a jóvenes que no se "activan" espontáneamente. A modo de ejemplo, podemos mencionar el caso de Eugenia, quien asistía a las reuniones del programa "en nombre" de su marido. La pareja tenía cuatro hijos y convivía, generalmente, en el mismo hogar. Él correspondía con la definición del perfil, porque había estado preso por robo y seguía vinculado con el delito y con el consumo de alcohol. En un comienzo, los operadores intentaron que el marido de Eugenia concurriera al programa. Asistió a una reunión en la que conversé con él; me contó que había estado preso y manifestó que quería cambiar, ya que tenía miedo de perder a su familia. Destacó que su mujer tenía mucha paciencia, porque soportaba que él anduviera "de gira" por varios días cuando consumía alcohol o drogas, ausente del hogar.

Pese a la expresión de esta voluntad, nunca más asistió a las reuniones y Eugenia explicó que no podía convencerlo que de que fuera y que no sabía cómo manejar esta situación. Después de algunas discusiones, los operadores decidieron incorporar a Eugenia como beneficiaria, con el propósito de contenerla para que pudiera convencer a su marido de asistir al programa. Con el paso del tiempo, la contención de Eugenia implicó que se separara de su marido para dejar de sufrir agresiones físicas. De este modo, Eugenia asistía al programa sin ser del perfil, pero con el propósito de incorporar un nuevo beneficiario, aunque esto nunca se hubiera alcanzado.

\subsection{Reclutamiento y estigmatización}

Al mismo tiempo que se deben sortear las dificultades de encontrar al beneficiario del perfil y un equilibrio entre la reserva de un recurso para estas personas y la posibilidad de otorgarlo a personas con mayor visibilidad y 
disponibilidad, en un contexto de escasez de recursos y alta demanda de planes sociales, es preciso considerar otro problema que surge de la consideración de alguien como beneficiario de un plan de prevención del delito. En primer lugar, porque algunas traducciones prácticas de la definición del perfil implicarían que todos los jóvenes residentes en una "comunidad vulnerable" son potenciales beneficiarios del programa y, por ende, podrían ser considerados "en conflicto con la ley penal". Cabe preguntarse si el recorte de beneficiarios estigmatiza a los jóvenes del barrio en general y, en alguna medida, a la villa.

En segundo término, más allá de la utilización de los términos políticamente correctos (comunidades vulnerables, jóvenes en conflicto con la ley), la definición de este público para ser beneficiario de un programa que previene el delito nos obliga a problematizar los señalamientos que indican que se trata de iniciativas propuestas como respuesta a demandas de seguridad de otros sectores de la población (Pegoraro, 2002; Ayos y Dallorso, 2011).

Para comenzar a analizar los posibles procesos de estigmatización que se producirían en la práctica, sugerimos ir al inicio de la relación entre un beneficiario y el programa. Este comienzo supone, por el motivo que fuera, que los operadores clasifican a un joven como beneficiario. Así, en virtud de esa clasificación, se otorga, al mismo tiempo, una serie de atributos y el acceso a un dinero mensual. Esta transformación del joven en beneficiario se produce con independencia de sus características personales. ${ }^{12}$

Ahora bien, en la práctica, hay una clasificación por parte de los operadores en dos tipos de beneficiario: quienes cumplen con el perfil y quienes no lo cumplen. Aquí se evidencia uno de los distanciamientos entre el diseño institucional del programa y sus aplicaciones prácticas: los beneficiarios clasificables en el perfil pueden transitar una serie de actividades y recorridos que (más allá de la evaluación de su efectividad o pertinencia) ha sido pensada y diseñada para ellos, mientras los beneficiarios que no lo cumplen deben portar algún atributo o relación que los convierta en aptos para seguir siéndolo.

12 Más adelante, analizaremos los sentidos y efectos que esta clasificación adquiere en la práctica y discutiremos si implica la estigmatización de los beneficiarios. 


\subsubsection{Beneficiarios no perfil}

Entre los operadores se generaban reiteradas discusiones acerca de por qué seguir incluyendo a ciertos beneficiarios cuando no clasificaban dentro del perfil. Los acuerdos o las razones por las que alguien que no correspondía al perfil debía ser incluido en el programa eran conocidas por el beneficiario, por lo cual, en muchas ocasiones, era posible observar ciertas tensiones entre el acuerdo particular realizado con el joven no perfil y las actividades "normales" del programa. Por ejemplo, Eugenia muchas veces no asistía a las reuniones del programa porque era sobrepasada por sus tareas en el comedor. Esto en ocasiones generaba molestias entre los operadores, puesto que se esperaba que ella participara de las reuniones con los otros beneficiarios para mostrar un punto de vista que podía ser positivo para los chicos. En el caso de otros beneficiarios, se acordó que debían dar cursos de oficios para sus compañeros. En general, se esperaba que los beneficiarios no perfil hicieran algún aporte al trabajo con los beneficiarios con perfil.

Quienes no tenían el perfil eran aceptados en el programa porque cumplían con alguno de los siguientes criterios:

a) Permitían llegar a quien tiene el perfil y mantiene alguna relación con el beneficiario no perfil. Este es el caso de Eugenia y, en alguna medida, el caso de Ana:

Conocí al marido de Ana. Se llama Emilio, estaba con los hijos. Le faltan los dientes de adelante, es muy alto, tiene el pelo largo y se lo ve desaliñado. Ella dice que él necesita ir al programa. María Clara le pregunta por qué no se queda "Juan", ella le responde que no le cambie el nombre porque él le va a pegar una piña. María Clara dice que tienen que hablar de eso, ella responde que no le pega, que la que le pega es ella. Pero que no puede venir al programa porque alguien tiene que cuidar a los chicos, llevar a la nena al colegio, a lo mejor la puede llevar la suegra, dice después. María Clara le dice que con solo ver al marido se da cuenta de que él necesita el programa y ella dice que sí (nota de campo, 20 de marzo de 2007). 
b) Facilitaban "sostener" a alguien durante un tiempo limitado, lo cual implica que se compromete a hacer algo (terminar la escuela, buscar trabajo, etc.).

c) Vivían en alguna zona de la villa en donde el programa no era conocido y su incorporación podía servir para alcanzar a jóvenes con el perfil de esas zonas. Si bien esta estrategia me fue relatada, nunca vi que se aplicara a alguien o que los operadores salieran a áreas en donde el programa no era conocido.

Esta diversidad de perfiles no debe llevarnos a pensar que las actividades del programa se desarrollan en compartimentos estancos o que la dinámica de interacciones cotidianas del barrio no involucra a jóvenes perfil con los que no lo son.

Es importante tener en cuenta que la conciencia acerca del hecho de tener un recurso a distribuir requiere que los operadores se manifiesten proclives a privilegiar la entrega del recurso por encima de su conservación. En definitiva, propiciar una estricta clasificación de los beneficiarios implicaría negar el acceso a un recurso aun en el caso de que este estuviera disponible.

\section{Reclutamiento: aceptación o rechazo}

Los propios beneficiarios proponían la incorporación de un amigo, un vecino o un pariente al programa. Por lo tanto, el reclutamiento tendía a la aceptación o al rechazo de las propuestas de beneficiarios $\mathrm{u}$ otros miembros de la comunidad, o sea, era más frecuente que los jóvenes fueran a presentarse como posibles beneficiarios que las salidas a buscarlos.

Una de las consecuencias de estos modos de vinculación era que la conformación del grupo de beneficiarios siempre implicaba que todos compartieran el espacio al menos con un amigo o pariente. Esto muestra que la trama de las relaciones sociales propia de la villa puede imponerse a la lógica propuesta por el programa.

También hay personas que colaboran con el programa, actores comunitarios, que participan del reclutamiento de beneficiarios. Quienes manejan el comedor comunitario en donde se desarrollan las actividades del pro- 
grama (las chicas del comedor) tienen una amplia capacidad de proponer posibles beneficiarios.

Además, el hecho de desarrollar las actividades en el comedor implica que los operadores tengan contacto casual no solo con sus encargadas, sino también con los vecinos que van a comer. Esto conlleva la creación de espacios en los que alguna de las chicas puede sugerir a alguien que hable con los operadores y les solicite su ayuda.

En estas etapas, la tarea de los operadores consiste en cubrir la cantidad de vacantes disponibles (relacionada con la cantidad de PEC que se brinda al programa en cada momento), reclutar beneficiarios y procurar cierto equilibrio entre los tipos de beneficiarios señalados.

Durante el tiempo que duró mi trabajo de campo, hubo períodos en los que había más aspirantes que vacantes, así como otros en los que se ofrecía un mayor número de vacantes. En los tiempos de escasez de vacantes, la labor de reclutamiento se limitaba a aceptar o rechazar las solicitudes espontáneas de beneficiarios y actores comunitarios. En general, la respuesta consistía en la propuesta de que el potencial beneficiario asistiera a algunas reuniones para probar "si podemos trabajar juntos" sin ser considerado un beneficiario formal y, por lo tanto, sin acceso al beneficio económico (período de admisión).

En cambio, en las épocas de abundancia de vacantes, son los operadores quienes invitan a beneficiarios y actores comunitarios que acerquen potenciales beneficiarios, como puede verse en la siguiente nota de campo: "Ernesto hizo entrar a todos para preguntar si tenían a alguien que no fuera un pariente que quisiera entrar al programa, que tenían varias vacantes para dar" (nota de campo, 18 de julio de 2006).

Hubo momentos cuando la preocupación en el reclutamiento estuvo centrada en privilegiar el ingreso de beneficiarios perfil con las ya mencionadas implicaciones. En otros instantes, el interés se enfocaba a "salir de la manzana del comedor", por lo que se recurría a actores comunitarios con quienes se tenía una relación menos cercana que con las chicas del comedor.

Entonces, cabe resaltar que, frente a lo estipulado programáticamente, las prácticas de reclutamiento son dinámicas y se reconfiguran frente a coyunturas específicas. Ahora bien, el criterio principal para determinar la cantidad de beneficiarios fue siempre la cantidad de PEC disponibles, sin considerar las efectivas posibilidades de trabajar sobre la transformación de 
cada beneficiario. Así se originaba una relación de escasez de operadores en función de la cantidad de beneficiarios. ${ }^{13}$

\subsection{Presentación del beneficiario en la trama cotidiana}

La relación operador-beneficiario comienza a construirse con una breve interacción por la que el operador recaba las primeras impresiones sobre el beneficiario mientras explica el programa. En los primeros tiempos, en la villa, algunos operadores recuerdan haber sido sospechosos de ser policías o narcos, mas las interacciones posteriores al reclutamiento estaban sostenidas en las referencias de los beneficiarios o actores comunitarios que recomiendan nuevos integrantes del programa.

El primer encuentro entre operadores y beneficiarios potenciales parecía estar signado por el manejo estratégico de la información para adaptarse a lo que los jóvenes suponían que se buscaba. ${ }^{14}$ Como señala Goffman (1994), es posible intentar controlar la conducta de los otros, al influir en la definición de la situación de la persona en la vida cotidiana. En la medida en que los otros actúan como si el individuo hubiera transmitido una impresión determinada, podemos decir que ha proyectado con eficacia una definición particular de la situación..$^{15}$

El control inicial de la información se genera cuando quienes quieren ser beneficiarios o lograr que otro lo sea no necesariamente están al tanto del perfil buscado por el programa, por lo cual deben manejar la presentación del beneficiario y suponer ciertas expectativas. Por ejemplo, presencié casos en los que alguien pedía ser considerado para entrar al plan y preguntaba si el hecho de no saber leer y escribir lo inhabilitaba para hacerlo. ${ }^{16}$

13 Esta relación, pensada en términos de escasez de operadores, requería la aceptación con beneplácito de la llegada de voluntarios, que no está contemplada en la documentación. Esta falta de recursos es lo que permitió, entre otras cosas, mi acceso inicial al campo.

Nos referimos a una apreciación de los operadores. El número corresponde a un momento de mi trabajo de campo de tres operadores y en otro, de cuatro para unos treinta (cuando hay menos) o cuarenta beneficiarios. Es importante considerar que no todos asisten a todas las reuniones.

14 Esto coincide con lo que señalan Litichever y otros autores (2013) acerca de las adaptaciones hechas por los sujetos para ser parte del grupo social que los define como su población destinataria.

15 Así, se genera un potencial juego infinito de información de secreto, descubrimiento, falsa revelación y redescubrimiento (Goffman, 1994).

16 No podemos afirmar taxativamente las situaciones por las cuales estos jóvenes creyeron que debían saber leer y escribir para ser beneficiarios del programa, pero suponemos que pudo 
El suceso más frecuente era que el potencial beneficiario fuera presentado como alguien que "tenía problemas", sin que se ahondara en explicaciones. Otras veces, los aspirantes a beneficiarios manifestaban que su intención de ingresar al programa se relacionaba con la necesidad de "no estar en la calle". En otras ocasiones se daba un poco más de información: "Llegaron Solange y Natalia con una amiga, Marianela, que le dijo a María Clara que venía porque tenía problemas en la casa con el marido" (nota de campo, 27 de marzo de 2007).

Ya sea que se contara con una referencia general de alguien que tiene problemas o que se especificaran problemas en la casa con el marido, se trataba de una situación inicial de conocimiento mutuo, que no surgiría si no se conociera en la villa que el programa busca trabajar con "chicos con problemas", frase con la cual escuché a Ernesto referirse al perfil buscado en varias oportunidades.

El hecho de presentarse o presentar a otro como alguien con problemas nos indica que hay una búsqueda de adaptación por parte de los jóvenes por incidir en la idea inicial que los operadores pueden hacerse de ellos, con el propósito de ser aceptados como beneficiarios. Esto no implica que los problemas sean falsos, sino que es un tipo de introducción que se hace en una situación específica con objetivos particulares.

Una de las consecuencias de este tipo de presentación señalado por Litichever y otros autores (2013) es que se elude el dinamismo de la situación de vida de los jóvenes, pues intentan satisfacer los requerimientos institucionales de permanencia.

En cualquier caso, ser clasificado como beneficiario implica adquirir la condición de "chico con problemas", al menos en algunos contextos y esto nos remite al problema de clasificación y estigma. Becker (2009) analiza los efectos de la clasificación de las personas como desviadas y entiende que, cuando alguien es detenido por un delito específico, el individuo queda expuesto a ser indeseable en otros aspectos también. Así, tratar a un individuo como si fuese un desviado en general y no una persona con una desviación específica tiene el efecto de producir una profecía autocumplida. ${ }^{17}$

surgir por el hecho de que muchas veces las actividades del programa tenían una primera instancia en la que cada uno escribía siguiendo ciertas consignas.

17 Postulamos que la situación es más compleja que lo señalado por Becker (2009) y que los 
En esta instancia, presentarse como una persona con problemas o que ya no quiere estar todo el día en la calle no tiene mayor incidencia en términos de estigmatización en un contexto acotado como el del programa. Al contrario, sentir que se convenció al operador de ser aceptado me ha sido relatado por un beneficiario con orgullo, como una hazaña. ${ }^{18}$

Otra estrategia seguida por un grupo minoritario de potenciales beneficiarios para presentarse y conseguir el recurso consistía en exhibir su capital físico, es decir, se trataba de mostrar alguna capacidad de daño que intimidara a los operadores, al punto de tener que aceptar a los beneficiarios. Observé algunos jóvenes que, en las primeras reuniones, hacían movimientos para evidenciar que tenían armas bajo sus ropas. En otra oportunidad, Osvaldo me contó que cuando pidió a "los peruanitos" que lo esperaran para hablar, escuchó que uno de ellos decía que si no lo anotaban, lo iba a "cagar a trompadas".

\subsubsection{Una presentación con información incompleta}

En una primera instancia, la intuición de los operadores es un elemento clave para definir quién puede tener el perfil del programa: un tatuaje en el cuello, el aspecto o el modo de hablar podía indicarlo. Es preciso reflexionar acerca de las clasificaciones que pueden hacer las instituciones. Míguez (2008) retoma los análisis de Cicourel (1995) en los juzgados de Estados Unidos, en donde se verificaba el uso de un conocimiento informal como mediación entre la taxonomía legal y los procedimientos específicos. Míguez (2008) encuentra un mecanismo similar en los juzgados de menores en Argentina.

Esta falta inicial de información puede obedecer a que quienes recomiendan al potencial beneficiario hubieran decidido ocultarla o no la posean. Además, en el diálogo inicial con el potencial beneficiario, hay ciertas pre-

efectos de este tratamiento no son tan lineales y tienen distintas repercusiones en diferentes ámbitos; sin embargo, es conveniente tener presente y analizar estas afirmaciones puesto que, si algo tiene de cierto esta aseveración, nos encontramos frente a la paradoja de que las instituciones destinadas a transformar a una persona para producir una inserción social conllevan la profundización de vidas desviadas.

18 Este relato se produjo en una conversación con un beneficiario fuera del contexto del programa tras haber ganado su confianza. 
guntas establecidas que no siempre se hacen y se enfocan más a clasificar rápidamente al beneficiario, sin incomodarlo con demasiadas preguntas.

“Conocimos a Hernán. Tiene 24 años, estuvo preso seis años, casi siete en Ezeiza. Y antes de eso, nueve meses en el Belgrano. Ernesto le dijo: 'Claro, robo con arma de guerra' y Hernán asintió" (nota de campo, 5 de diciembre de 2006).

Tiempo después, el propio Hernán contó que, en realidad, su condena había obedecido al asesinato de un policía. Los operadores entendieron este hecho como que Hernán no había querido contar, en un principio, el verdadero motivo de su condena. Sin embargo, la oportunidad le fue ofrecida para hacerlo de ese modo, como parte de esta estrategia para que el potencial beneficiario se sintiera cómodo y también para presentarse como personas que conocen el barrio y manejan información más allá de la voluntad del beneficiario. ${ }^{19}$ Goffman (1994) entiende que, cuando un individuo llega ante otros, estos tratan de adquirir información (o de poner en juego la que poseen) para definir la situación. La información permite a los otros saber de antemano lo que él espera de ellos y lo que ellos esperan de él.

Entonces, en una primera instancia, los operadores intentan recabar información sobre hechos que pueden clasificar al beneficiario como perfil o no perfil, pero esta tiene que ver menos con hechos concretos que con la intuición. No obstante, en un inicio, esto parece poco importante para ellos, puesto que se considera que, con el tiempo, se irá adquiriendo confianza para conocer más sobre la vida de los jóvenes. En cambio, se presta más atención a la información ligada al ámbito familiar en el que se mueve el beneficiario, sobre todo para determinar si se busca solo el dinero o hay algún "interés genuino".

Más allá de los modos como se hace esta clasificación inicial en la práctica, se cuenta con una ficha estandarizada para aplicar cuando alguien desea ingresar al programa. En ella, cobran relevancia ciertos clasificadores supuestamente objetivos como el consumo de drogas, las causas abiertas o las detenciones. Esta presunta objetividad de los sistemas de clasificación burocráticos se encuentra con otra realidad en la villa y, además, siempre se cuenta con la posibilidad de que, en esa primera entrevista, el potencial

19 Observé la práctica de los operadores de mostrarse como conocedores del barrio a partir del manejo de información que los jóvenes suponen vedada en el período de admisión. 
beneficiario mienta: en efecto, puede decir que consume drogas, aunque no lo haga, si asume que de esa manera será inscripto en el programa o puede no reconocer que lo hace porque lo considera contrario a lo esperan de él.

Por lo tanto, a pesar de que esas fichas se aplican más o menos sistemáticamente y se archivan en la oficina para cumplir con rutinas ritualistas, nunca vi que les dieran algún uso específico. Mientras, las primeras impresiones que los operadores construyen sobre el beneficiario, independientes del discurso del mismo, son constantemente referidas. En estas impresiones, resulta mucho más fiable la información que brindan los actores comunitarios. Por ejemplo, en una oportunidad, una beneficiaria se presentó y señaló que había dejado el consumo de drogas porque se había dado cuenta de que eso "no le servía para nada" y, cuando terminó la entrevista con María Clara, se acercó una de las chicas del comedor a decirle que la piba era una mentirosa y un cachivache. ${ }^{20}$

El estudio de Zapata (2005) sobre el voluntariado de Cáritas discute algunas cuestiones que vale la pena retomar. La autora señala que las voluntarias ven a las familias beneficiarias como amenazantes, porque pueden sesgar la información que dan de sí mismas y se genera una clasificación práctica de las beneficiarias como "vivas" o "buenas madres". Si bien estamos abordando dos realidades y actitudes diferentes, nos interesa destacar que, en ambos casos, encontramos clasificaciones prácticas que, en la trama cotidiana, aparecen a merced de la intuición e implican una evaluación moral sobre el sujeto de intervención.

Por otra parte, no toda la información obtenida en esta etapa es de orden textual. Goffman (1994) analiza la expresividad de los actores como la capacidad para producir impresiones e indica que está compuesta por la expresión que da y la expresión que emana (este segundo tipo puede ser tratado por los demás como sintomáticas del actor). La expresión que surge es no verbal, más teatral y contextual, quizás involuntaria. ${ }^{21}$

Los operadores toman algunos de esos rasgos como un tipo de información. En consecuencia con lo planteado por Goffman (1994), se entiende

20 Involucrada en delitos menores dentro del barrio.

${ }^{21}$ Los integrantes del auditorio sienten que los actuantes dan una impresión que es verdadera o falsa. Es una duda común y, por eso, se presta atención a rasgos distintivos de la actuación que no pueden ser manejados con facilidad. Tanto el actuante honesto como el deshonesto deben tener cuidado de animar sus actuaciones con las expresiones adecuadas. 
que hay rasgos de esa expresividad emergente que son más auténticos -en tanto son involuntarios-y son los que sirven a la construcción de esa definición intuitiva del beneficiario.

Los beneficiarios no solicitan información en la primera entrevista. En general, cuando llegan a hablar con los operadores ya conocen el hecho de que el programa implica el cobro de un PEC y son los operadores quienes aclaran que ello ocurrirá cuando se produzca una vacante, lo cual no sucederá de inmediato. Tampoco solicitan información acerca de lo que se espera de ellos y se limitan a responder de la forma más escueta posible las preguntas de los operadores y a escuchar las mínimas pautas de trabajo que enuncian los operadores: "No se puede chorear; hay que venir los martes y los jueves y ya nos vamos a ir conociendo y, si necesitás algo, nos pedís".

\subsection{La transferencia monetaria: factor de atracción en el reclutamiento}

Mediante la articulación con el Ministerio de Trabajo, el programa ofrece un Plan de Empleo Comunitario para los jóvenes. Esto explica, en la mayoría de los casos, el motivo por el que los jóvenes se acercan a proponerse como beneficiarios. Entonces, este recurso del dinero genera un beneficio para los jóvenes y explica su asistencia al programa, al mismo tiempo que configura una relación económica entre operadores y beneficiarios y otorga a los operadores un poder (aunque condicionado por algunas reglamentaciones externas) sobre los beneficiarios.

Ahora bien, esto no implica que la relación fuera económica o que no pudiera tener contenidos afectivos. Zelizer (2009) muestra holgadamente que la gente mezcla sus relaciones privadas con sus relaciones económicas, sin limitarlas a alguno de los dos ámbitos.

Es preciso hacer algunas aclaraciones respecto al monto del dinero percibido por los beneficiarios: la suma de $\$ 150$ no parece poder competir en términos económicos con los beneficios reportados por algunas actividades delictivas. Sin embargo, el hecho de obtener una suma fija de dinero todos los meses implica un aporte a las economías de muchos hogares. Esta suma de dinero no se modificó en todo el tiempo que duró mi trabajo de campo, pese al contexto inflacionario en el que se desarrolló, que permite suponer 
una reducción en el poder de compra, por más que siguiera siendo una suma con alguna importancia.

La transferencia de este dinero plantea algunas cuestiones sobre las que vale la pena detenerse para analizar el sentido que adquiere para los actores implicados.

Después me habló de que algunos chicos están realmente "enganchados" con ellos, mientras que otros "se hacen los interesados" por la plata. Hablamos de lo que significan los 150 pesos para ellos, "son como 1.500 para nosotros [...]. Ellos no viajan, no pagan servicios". Lo que hacen ni bien compran el primer subsidio es sacarse un crédito para tener un celular, que vos no te comprarías o unas zapatillas que valen 500 pesos (nota de campo, 11 de octubre de 2005).

En esta nota, que reproduce un diálogo con Ernesto, pueden observarse tres preocupaciones más o menos constantes sobre el dinero como aspecto problemático de la relación. El primero, se relaciona con la duda permanente por parte de los operadores acerca del grado de confianza logrado en el barrio y el dinero: si es solo el dinero lo que explica la confianza que los vecinos depositan en ellos, qué pasaría si no tuvieran el PEC y cómo se interpretan los acercamientos afectivos de los beneficiarios y su grado de compromiso (si alguien quiere cambiar o está comprometido con ellos o si solo está por el dinero).

El segundo problema se vincula con la idea de que lo que ellos dan parece poco, pero es mucho, porque sus condiciones de vida les demandan menos gastos y porque -aquí viene el tercer problema- son chicos y solo tienen gastos superfluos.

Si bien la mirada de los beneficiarios no necesariamente coincide con la de los operadores frente a que el dinero es mucho, puede afirmarse que se trata del cobro de un dinero muy significativo. Ya sea que se trate de jóvenes que se han independizado o que viven con sus familias de origen, es un dinero que se aporta a una economía hogareña y su falta produce malestares. Esto no quiere decir que el PEC sea el único plan que se recibe en una casa o el único ingreso, sino que en la lógica del cazador (Merklen, 2005) ninguno de los componentes que aportan a los ingresos de un hogar es despreciable. 
Uno de los principales atractivos del PEC es que, a diferencia de otros ingresos como los que provienen de trabajos inestables o de actividades delictivas, implica la percepción de un ingreso mensual fijo. Esto es decisivo, porque permite que las personas se endeuden y obtengan recursos que, de otro modo, estarían fuera de su alcance. ${ }^{22}$

Algunas ideas de este orden son captadas por los operadores, quienes consideran que este dinero, en la economía de la villa, alcanza para cubrir necesidades básicas.

Por su parte, en algunos hogares, la idea de la "acumulación de planes" constituye una preocupación central para los operadores. Se busca detectar desde el principio a quienes intentan vivir de planes o a quienes son mandados por la familia. Ambas conductas son desaprobadas y, como las modalidades de reclutamiento privilegian la llegada de recomendados por beneficiarios, son frecuentes las discusiones entre los operadores acerca de no permitir la acumulación de planes, puesto que ello no implica el inicio de un proceso de transformación, sino de una economía dependiente que tiende a estabilizarse en esa condición. A partir de una serie de reuniones se estableció que, para dar el alta a un pariente de un beneficiario, se esperaría a que el beneficiario más antiguo egresara. Incluso, cuando se presentó una pareja de potenciales beneficiarios a quienes Luciana quería incluir porque respondían perfectamente al perfil ("él roba y se droga y ella no lo aguanta más". Nota de campo, 11 de septiembre de 2006), el resto del equipo decidió que no se podía dar el alta a los dos a la vez, aunque estuvieran separados.

Como puede suponerse, la idea del programa y de los operadores es atraer a los jóvenes a partir de la posibilidad de cobrar un dinero fijo mensual, al tiempo que constituye la posibilidad de exigir, como contrapartida, la asistencia a reuniones en las que se otorgan otros beneficios, menos tangibles, a disposición de los jóvenes. Sin embargo, esta preocupación de los operadores acerca de la cantidad de planes de un hogar y de qué se hace con la plata - que por momentos parece excesiva- puede comprenderse si se la pone en relación con la preocupación de quienes no están interesados, mienten o "son falsos". Podemos postular que, en esta etapa de

22 Wilkis (2010) muestra la pertinencia de estudiar los comportamientos financieros de los sectores populares que, por lo general, son dejados de lado porque se los considera desmonetizados. 
reclutamiento, la función del dinero es la de atraer beneficiarios y esta atracción se produce, en general, gracias a una promesa de dinero, puesto que casi nunca el reclutamiento implica el cobro inmediato del PEC, sino que antes suele pasarse por una etapa de admisión, en la que se adquirirá la condición de beneficiario formal. ${ }^{23}$ Ahora bien, esta función está sujeta a ciertas ambivalencias morales, pues se intentará que atraiga lo suficiente como para querer ingresar al programa, pero no tanto como para querer ir "solo por la guita".

En síntesis, en el diseño institucional del programa, el dinero cumple una marcada función en términos de atracción a beneficiarios para tener la oportunidad de producir su transformación, pero a merced de los posicionamientos subjetivos de los operadores (respecto a quiénes lo merecen o a controlar cuáles familias lo reciben), hay una tendencia a que las preocupaciones por la búsqueda del perfil adecuado cedan ante la tentación de brindar el recurso a quien lo merezca.

\section{Producción de beneficiarios y encuentros de sistemas de clasificación}

La inserción del programa en la villa inicia una relación entre dos sistemas de clasificación: el del diseño institucional y el de quienes intentan ingresar o hacer ingresar a otros al programa. Este encuentro muestra que aun aquellos aspectos de la definición que pueden parecer precisos en una lectura de la documentación son apropiados de diversas maneras en el territorio.

El hecho de tener una causa abierta parece un factor más específico, tangible y objetivo; sin embargo, no siempre se conoce esta información antes de aceptar a un beneficiario.

Aún más importante, algunos jóvenes desconocen su propia situación legal (por ejemplo, ignoran si tienen una causa abierta o no): recuerdan haber tenido algún tipo de altercado con la Policía o haber estado en la

23 Este período de admisión es exceptuado por aquellos jóvenes que entran al programa por solicitud judicial (cuando salen de su situación de privación de libertad). En esos casos, la aceptación del beneficiario es inmediata, así como su inscripción formal en el programa y el cobro del PEC. 
comisaría, pero se desconoce si esto tiene o no consecuencias legales. Ello muestra que las taxonomías estatales que pueden parecer transparentes para la racionalidad burocrática adquieren distintos significados en contextos específicos. Entonces, este criterio "objetivo" para clasificar a un potencial beneficiario puede presentar tantas dificultades como cualquier otro:

-Pero... vos, ¿tenés alguna causa?

-Creo que no.

- ¿Por qué creés?

-Porque me escapé del hogar, pero eso no te hace una causa, ¿no? (nota de campo, 24 de abril de 2007).

En otros casos, me comentaron que en alguna oportunidad habían sido llevados a una comisaría, pero desconocían si ello implicaba la apertura de una causa. ${ }^{24}$ Esta situación también era percibida por los operadores.

Como vemos, los criterios para clasificar a un beneficiario no contemplan de antemano la posibilidad frecuente de que no siempre el propio joven cuente con la información para catalogarse dentro de las taxonomías estatales. Pese a ello, es posible ser admitido, sin necesidad de determinar con exactitud la situación legal.

Otro modo de evidenciar este encuentro entre sistemas de clasificación y sus correspondientes desplazamientos de un diseño institucional a prácticas específicas es la documentación requerida para ser beneficiario y las soluciones encontradas ante su carencia.

En efecto, el PEC solo puede ser cobrado por personas poseedoras de un documento nacional de identidad (DNI). Esta es una de las tantas circunstancias que no es del todo apropiada para la realidad de la villa, en donde residen muchos jóvenes indocumentados. Frente a esta situación, un procedimiento bastante utilizado era la recomendación de que el beneficiario consiguiera a alguna persona de su confianza que estuviera dispuesta a anotarse legalmente como beneficiario del programa y a pasarle el dinero todos los meses. Ahora bien, este procedimiento dejaba en manos de los jóvenes la resolución de los conflictos que pudieran producirse entre el beneficiario en los papeles y el beneficiario en la práctica.

24 En algunos casos, esto se refiere a abusos policiales. 


\subsection{Perfil y no perfil: la búsqueda de un equilibrio}

La búsqueda de un equilibrio entre la cantidad de beneficiarios con perfil y los que no lo tienen es una tarea que se construye día a día. Durante algunos momentos, los operadores mostraron especial interés en trabajar con jóvenes que respondieran de manera inequívoca al perfil. No obstante, el método de reclutamiento continuó basándose en las recomendaciones antes descriptas. En esos períodos, quienes recomendaban y quienes intentaban acceder al programa presentaban al candidato como apropiado. En una oportunidad, Mariana le dijo a una operadora que iba a "traer una chica que andaba callejeando y dejó los estudios, pero que la van a ver y van a pensar que es como ella" (dijo señalando a su propia hija que no respondía al perfil del programa).

\section{La admisión: asistencia}

Además de la clasificación, hay una serie de eventos que el beneficiario debe vivir en la etapa de admisión antes de ser aceptado en el programa. En la práctica, lo más significativo para los implicados es que el beneficiario no cobra el PEC hasta que le den el alta. Por lo general, esto ocurre cuando se produce una vacante; por lo tanto, el tiempo que un beneficiario debe permanecer en esta situación es variable.

En esta instancia, he observado un sinfín de casos de potenciales beneficiarios que se han presentado y han sido reclutados, pero no cumplen con la asistencia en el período de admisión y son olvidados por el programa. Sobre ellos no se lleva ningún registro.

Como en algunos momentos los operadores mostraban una preocupación por no darle más de un plan a una familia, cada vez que algún beneficiario estaba por abandonar el programa tenía la intención de (ahora que se podría) "pasárselo" a alguien de su familia. En estos casos, el nuevo beneficiario podía adelantar el período de admisión y pasar tiempo con su pariente (futuro exbeneficiario) en la reunión y asegurarse de ser tenido en cuenta a la hora del alta. 
El padre de los chicos dispuso que este chico acompañe a Diego para cuidarlo, que pruebe unos meses cómo se siente y que después se compromete a conseguirle un trabajo a Diego. La decisión de Ernesto es que recién cuando Diego sea dado de baja después de tres meses, se le va a dar el plan al hermano, porque "no le vamos a dar dos planes a la familia" (nota de campo, 5 de septiembre de 2006).

Este período de conocimiento que supone la etapa de admisión sirve para cuestiones elementales como aprender el nombre de los beneficiarios. Por ejemplo, un grupo de chicos peruanos fue llamado durante mucho tiempo "los peruanitos", hasta que se superó esta instancia. Se trata, sobre todo, de una fase en la que los operadores elaboran una evaluación del beneficiario y, muchas veces, se pregunta si alguien merece el plan.

Detrás de esta evaluación, también hay un debate por modalidades de conceptualización del pobre y de la pobreza. Lo mismo ocurre en la teoría social, en la que hay posicionamientos que no son neutros: es posible hablar de pobres, marginales o excluidos.

La pobreza aparece cargada de conceptualizaciones y prácticas sociales que se entrelazan y sedimentan, realidades que se parecen y se diferencian, representaciones, creencias, producción de multiplicidad de sentidos que proliferan, instituciones, agentes, soportes discursivos que hablan, nombran la pobreza y la lucha contra ella bajo diferentes máscaras (Redondo, 2004, p. 80).

Además, Litichever y otros autores (2013) advierten que los programas no abundan en definiciones sobre qué significan vulnerabilidades o riesgos. Por ello, es preciso estudiar la implementación de los programas, pues allí se emplean definiciones (implícitas o explícitas) acerca de las necesidades, que evidencian muchas veces las posturas morales de los agentes que aplican las políticas.

Contaron que después de hablar con Andrea la semana anterior (a donde habían ido Osvaldo y Lucas, mientras yo había acompañado a Ernesto al comedor) habían decidido que había chicos que se iban "a cansar de estar en lista de espera" a los que nunca les iban a dar el alta porque 
se habían enterado de que eran de "familias de narcos" y que estaban allí porque sus familias estaban interesadas en que tuvieran un plan (nota de campo, 13 de diciembre de 2005).

Esta nota muestra dos temas. Primero, hay beneficiarios que merecen más que otros el programa y ello no tiene que ver necesariamente con cumplir con los requisitos que definen el perfil, puesto que también podría pensarse que, si alguien es de una "familia de narcos", es imperioso que el programa trabaje con la persona. Entendemos que, para los operadores, el hecho de descubrir algo que les fue ocultado indica que la persona "no se abrió" y esto es lo que en buena medida inhabilita a los jóvenes como merecedores del plan. En segundo lugar, encontramos la persistente idea de que los planes son para la familia. Si bien los beneficiarios legales son personas, desde la perspectiva de los operadores, el plan se otorga a una familia.

\section{Comentarios finales}

El análisis nos permite comprender que la aplicación de una política de prevención social del delito constituye un proceso mucho más dinámico de lo que los trabajos centrados en lo programático permiten suponer.

Las ideas presentadas por Guemureman (2015) acerca de que la noción de sujeto es sustituida por la noción de factor o de que se trata de jóvenes clasificados como jóvenes en riesgo merecen ser interrogadas. En efecto, vimos que el proceso de reclutamiento y admisión abarca múltiples miradas, evaluaciones y clasificaciones; no se verifica una clasificación basada en las nociones de riesgo que se imponga con comodidad sobre sujetos sin agencia.

Evidenciamos que los jóvenes buscan el ingreso al programa, sin mostrar preocupaciones por lo que ello implica en términos de clasificación y de ninguna manera conlleva la plena aceptación de todos los contenidos del programa.

Además, es preciso retomar la idea de que responder positivamente a la aspiración de los jóvenes de acceder al PEC consiste en donarles un recurso, pero también clasificarlos como jóvenes en conflicto con la ley. Es discutible, si esto requiere un proceso de estigmatización y si el progra- 
ma puede acabar profundizando la exclusión que se propone solucionar. Se trata de estudiar los procesos microsociales de exclusión social en una política de inclusión social (Llobet, 2013).

Si cambiamos el ángulo de la mirada, podríamos preguntarnos si negar el recurso y evitar esa clasificación afecta en algo los procesos de exclusión o, por el contrario, niega aquello que los excluidos solicitan.

También es preciso anotar que la clasificación de los potenciales beneficiarios (según el diseño institucional, debería confirmarse en el período de admisión) se supone el punto más importante para diferenciar esta política de una política social cualquiera. No obstante, en la práctica, vemos que prima la lógica del intercambio y que en el reclutamiento no hay una voluntad explícita de aceptar solo a jóvenes del perfil (ni en el período de admisión una intención de seleccionar solo a quienes corresponda). Por lo tanto, no existe la voluntad de diferenciarse de una política social cualquiera que aparece en el diseño institucional. ${ }^{25}$ Habría que preguntarse si esta utilización de algunos beneficiarios de una política criminal como si fuera una política social no conlleva la criminalización de los mismos.

Como puede observarse, esta intención de ingresar al programa, relacionada en especial con el dinero, significa que jóvenes que de otro modo no serían considerados como "jóvenes en conflicto con la ley penal" (y que no se describirían a sí mismos de esa manera) se inscriban como beneficiarios $\mathrm{y}$, al mismo tiempo, se hagan acreedores del dinero y del rótulo.

Aunque esta clasificación puede ser leída en términos de estigmatización del beneficiario, se trata de una trama de percepciones más compleja, que funciona diferencialmente de acuerdo con el contexto en donde sea leído.

Por ejemplo, la pertenencia al programa podría implicar un estigma fuera de la villa, pero en ella, los jóvenes no muestran resquemor por el modo en el que el programa los nombra. Por el contrario, la mayoría de los beneficiarios se refieren al programa como "el plan" y muchos de ellos desconocen el nombre completo del mismo o sus objetivos. De todas maneras, no pretendemos afirmar que el desconocimiento de los propósitos

25 Insistimos en la importancia de abordar los efectos de las políticas públicas a partir de la observación de las prácticas. En este caso, la lectura de la documentación o las entrevistas a funcionarios podrían dar la idea de que el ejercicio del programa encuentra su diferencia fundamental con otras políticas sociales en una selección más o menos estricta del beneficiario. 
del programa impida suponer la existencia de la estigmatización o dominación. Sin embargo, tampoco contamos con evidencia que nos permita afirmar que existen estos procesos.

Por último, el dinamismo que describimos en la aplicación de la política no alcanza para incluir dentro de la misma a muchos de los jóvenes definidos por el diseño como población en riesgo. En efecto, estos jóvenes difíciles de alcanzar (Hendry, 2008) pueden ser reclutados por el programa, pero no sortean la etapa de admisión (porque no logran sostener la asistencia) y luego no se llevan registros de su paso por el programa. Así, las definiciones, apropiaciones y redefiniciones que tienen lugar en la práctica del programa no alcanzan para capturar el dinamismo que implica el día a día de los jóvenes en riesgo a quienes se les solicita una constancia que, en la mayoría de los casos, no consiguen.

No intentamos dar cuenta del desplazamiento ${ }^{26}$-que en efecto se produce- entre lo programado y la implementación, pues los mismos tienen que ver con la propia dinámica de la puesta en práctica del programa. Estudiar la aplicación del programa permite conocer las interacciones, los manejos de expectativas recíprocas, las apropiaciones y negociaciones que se producen allí. Este estudio muestra que las formas de clasificación y apropiación de las taxonomías involucran microprocesos de inclusión y exclusión social.

\section{Referencias}

Ayos, E. y Dallorso, N. (2011). (In)seguridad y condiciones de vida en la problematización de la cuestión social: políticas sociales y políticas de prevención social del delito. Política criminal, 6(11), 1-18.

Becker, H. (2009). Outsiders. Hacia una Sociología de la desviación. Buenos Aires: Siglo XXI.

26 Además, estos desplazamientos no implican hacer una crítica o exponer "errores" de quienes aplican las políticas. Aún más, los mismos operadores y coordinadores del programa, en sus reuniones de reflexión sobre casos críticos o de evaluación, notan estos desplazamientos, que son objeto de interrogación y discusión. Por el contrario, se trata de mostrar las prácticas que tienen lugar en la implementación de una política pública para analizar procesos microsociales de exclusión e inclusión. 
Ciafardini, M. (2005). Delito urbano en la Argentina. Las verdaderas causas y las acciones posibles. Buenos Aires: Ariel.

Cicourel, A. (1995). The Social Organization of Juvenile Justice. New Brunswik: Transaction Publishers

Dallorso, N. (2008). Intervenciones de las trabajadoras vecinales del Plan más vidaComadres en conflictos domésticos y barriales (Gran Buenos Aires, 2005-2007). Buenos Aires: Instituto de Investigaciones Gino Germani.

Douglas, M. (1996). Cómo piensan las instituciones. Madrid: Alianza.

Goffman, E. (1994). La presentación de la persona en la vida cotidiana. Buenos Aires: Amorrortu editores.

Guber, R. (1998). Identidad social villera. En M. Boivin, A. Rosato y V. Arribas (comps.), Constructores de otredad: una introducción a la Antropología Social y Cultural. (pp. 115-125). Buenos Aires: Eudeba.

Guemureman, S. (2015). Adentro y afuera. Juventudes, sistema penal y políticas de seguridad. Buenos Aires: Grupo Editor Universitario.

Hendry, T. (2008). Working with Hard to Reach Young People. A Practical Guide. Edimburgo: Gobierno escocés.

Herzfeld, M. (1993). The Social Production of Indifference. Exploring the Symbolic Roots of Western Bureaucracy. Chicago: University of Chicago Press.

Kelling, G. y Coles, C. (1997). Fixing Broken Windows. Restoring Order and Reducing Crime in our Communities. Nueva York: Touchstone.

Kessler, G. (2006). Sociología del delito amateur. Buenos Aires: Paidós.

Litichever, C., Magistris, G. y Gentile, F. (2013). Hacia un mapeo de necesidades y beneficiarios en los programas de inclusión social para niños, niñas y adolescentes. En V. Llobet (coord.), Sentidos de la exclusión social. Beneficiarios, necesidades y prácticas en políticas sociales para la inclusión de niños y jóvenes. (pp. 73-92). Buenos Aires: Biblos.

Llobet, V. (2013). Estado, categorización social y exclusión de niños, niñas y jóvenes. Aportes de los debates sobre la exclusión social a los estudios de infancia y juventud. En V. Llobet (coord.), Sentidos de la exclusión social. Beneficiarios, necesidades y prácticas en políticas sociales para la inclusión de niños y jóvenes. (pp. 23-50). Buenos Aires: Biblos.

Mancini, I. (2012). La prevención del delito en una villa de emergencia de la ciudad de Buenos Aires (Argentina). INVI, 27(74), 110-116.

Mancini, I. (2015). Prevención social del delito. Relaciones entre agentes estatales y jóvenes de sectores populares. San Martín: Unsam Edita.

Merklen, D. (2005). Pobres ciudadanos. Las clases populares en la Argentina democrática (1983-2003). Buenos Aires: Gorla. 
Míguez, D. (2008). Delito y cultura. Los códigos de la ilegalidad en la juventud marginal urbana. Buenos Aires: Biblos.

Míguez, D. y D'Angelo, L. (2006). Relaciones relativas: desempleo y delito en la provincia de Buenos Aires (1980-2000). Desarrollo Económico, 46(182), 267293.

Ministerio de Justicia y Derechos Humanos, Dirección Nacional de Política Criminal. (2005). Programa "Comunidades Vulnerables". Plan Nacional de Prevención del Delito. Buenos Aires: Autor.

Pegoraro, J. (2002). Las políticas de seguridad y la participación comunitaria en el marco de la violencia social. En R. Briceño León (comp.), Violencia, sociedad y justicia en América Latina (pp. 29-55). Buenos Aires: Clacso.

Ratier, H. (1975). Villeros y villas miseria. Buenos Aires: Centro editor de América Latina.

Redondo, P. (2004). Escuelas y pobreza. Entre el desasosiego y la obstinación. Buenos Aires: Paidós.

Sozzo, M. (2000). Seguridad urbana y tácticas de prevención del delito. Cuadernos de jurisprudencia y doctrina penal, (10), 34-82.

Wilkis, A. (2010). Capital moral y prácticas económicas en la vida social de las clases populares. Un estudio socioantropológico en el partido de la Matanza. (Tesis doctoral inédita). EHESS/UBA. Buenos Aires, Argentina.

Zapata, L. (2005). La mano que acaricia la pobreza. Etnografía del voluntariado católico. Buenos Aires: Antropofagia.

Zelizer, V. (2009). La negociación de la intimidad. Buenos Aires: Fondo de Cultura Económica. 
